\title{
Diálogos em multilinguismo: uma discussão sobre as pesquisas realizadas no LABICO/UFRGS
}

\section{Dialogs in multilingualism: a discussion on the studies conducted at LABICO/UFRGS}

Ingrid Finger ${ }^{1}$, Ubiratã Kickhöfel Alves², Ana Beatriz Arêas da Luz Fontes ${ }^{3}$, Elena Ortiz Preuss ${ }^{4}$

1 Doutora em Letras (PUCRS, 2000). Professora do Programa de Pós-Graduação em Letras da UFRGS. Coordenadora do Laboratório de Bilinguismo e Cogniçaao (LABICO/UFRGS), onde desenvolve a pesquisa "Traduçăo e adaplaçãa de uma tarefa de avalaçáa da capacidade de memória de trab

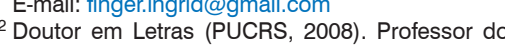
Programa de Pós-Graduação em Letras da UFRGS. Bolsista de Produtividade do CNPq - Nivel 2. Membro do Laboratório de Bilinguismo e Cognição (LABICO/UFRGS). Atualmente desenvolve instruçã̃o plosivas surdas e sonoras iniciais do inglês (LE) por aprendizes argentinos e brasileiros: o pape de pistas acústicas primordiais na L1".

E-mail: ukalves@gmail.com

Doutora em Psicologia Social, Cognitiva e Neurociencia (The University of Texas at El Paso, 2010) Letras da UFRGS Membro do Laboratório de Bilinguismo e Cognição (LABICO/UFRGS). Atualmente desenvolve as pesquisas "Processamento de ambiguidade lexical na L2" e "Acesso lexical em individuos bilingues e trilingues

E-mail: aninhafontes@icloud.com

Doutora em Estudos da Linguagem, com Espe(2011). Professora do Programa delás Pós-Graduaçấo em Letras e Linguística da UFG. Membro do Laboratório de Bilinguismo e Cognição (LABICO/UFRGS), desenvolvendo a pesquisa "Condiçôes pedagógicas e variáveis individuais na aquisição de linguas
RESUM0: A partir de uma visão de multilinguismo como um dilema intercultural, cujas características podem ser mais bem elucidadas a partir da condução de estudos interdisciplinares, este artigo tem como objetivo exemplificar de que forma o diálogo entre as várias áreas da Linguística e os diferentes campos do conhecimento enriquecem os estudos desenvolvidos no âmbito do LABICO/UFRGS. São apresentadas pesquisas sobre acesso lexical bilíngue, produção de fala bilíngue e percepção e produção de sons em língua estrangeira, com vistas a demonstrar de que forma uma atitude interdisciplinar contribui para ampliar o entendimento da natureza do processo de aquisição e uso da linguagem por indivíduos multilíngues, fomentando o debate sobre definições, teorias e metodologias que possam elucidar esse fenômeno tão complexo que é o multilinguismo.

Palavras-Chave: Multilinguismo; Interdisciplinaridade; Acesso lexical bilíngue; Produção de fala bilíngue; Percepção e produção de sons em língua estrangeira.

ABSTRACT: Conceiving multilingualism as an example of intercultural dilemma, whose characteristics can be better understood from an interdisciplinary view, this paper aims to present examples of studies conducted at LABICO/UFRGS, in which the different areas of Linguistics as well as several other knowledge domains are put together and interact. In particular, studies focusing on bilingual lexical access, bilingual speech production and perception and production of foreign language sounds are discussed in order to demonstrate the way an interdisciplinary perspective can broaden the comprehension of the complex process of multilingual language acquisition and use, shedding light on definitions, theories and methods that help elucidate this complex phenomenon.

KEYworDs: Multilingualism; Interdisciplinarity; Bilingual lexical access; Bilingual speech production; Perception and production of foreign language sounds 


\section{Introdução}

oucas coisas possuem um papel tão central em nossas vidas quanto a linguagem. É através dela que comunicamos nossos pensamentos e sentimentos, e que desempenhamos várias funções sociais. A diversidade com a qual usamos a linguagem em nosso cotidiano é impressionante e o uso da linguagem na interação com outros falantes ocorre de forma automática e com aparente facilidade e rapidez. Embora seja um fenômeno intrinsecamente social, o uso da linguagem envolve um sofisticado processamento linguístico e cognitivo e, no caso de falantes bilíngues ou multilíngues, esse processamento se torna ainda mais complexo. É nesse contexto que se inserem as pesquisas realizadas no Laboratório de Bilinguismo e Cognição, da Universidade Federal do Rio Grande do Sul (LABICO/UFRGS), que analisam de que forma as pessoas aprendem e processam outras línguas além da sua língua materna, com o objetivo último de contribuir para um maior entendimento de como a interação entre pessoas que falam mais de uma língua no mundo intercultural contemporâneo é possível.

Indivíduos bilíngues ou multilíngues não somente se comunicam com pessoas que falam mais de uma língua, mas também são capazes de compreender melhor diferentes culturas e formas de pensar, pois essa experiência faz com que suas mentes se adaptem às demandas linguísticas e conceituais das diferentes línguas que dominam. Assim, o multilinguismo é concebido como um dilema intercultural, cujas características podem ser mais bem elucidadas a partir de estudos interdisciplinares. A nosso ver, é justamente na interlocução entre as diversas áreas da Linguística e na interface com diferentes campos do conhecimento que podemos aprofundar teorias e metodologias e buscar uma maior compreensão do que caracteriza a aquisição e o uso da linguagem no caso de falantes bilíngues e multilíngues. A constituição do multilinguismo como uma área de pesquisa inter(trans) disciplinar (MIRANDA, 2008) possibilita o debate científico que leva em consideração um conjunto de complexidades que vão além do escopo de ciências específicas, transcendendo os espaços estritamente disciplinares.

Enfatiza-se, portanto, neste artigo, a necessidade de uma maior interlocução entre os pesquisadores dos Estudos da Linguagem, bem como de outras áreas do conhecimento. Tal tarefa será atingida através da exemplificação de como esse diálogo ocorre na condução das pesquisas realizadas no LABICO, que versam sobre temas relacionados ao processamento linguístico e cognitivo em contextos de bilinguismo unimodal (duas línguas de mesma modalidade) e bimodal (uma língua oral e uma língua de sinais), bem como de multilinguismo.

Para isso, na primeira seção, faremos uma breve discussão sobre bilinguismo e multilinguismo. A seguir, apresentaremos de que forma os estudos desenvolvidos pelos pesquisadores do LABICO/UFRGS exemplificam essa interlocução entre as áreas da Linguística e entre a Linguística e outros campos do conhecimento, a saber, nos estudos sobre o acesso lexical bilíngue, nas pesquisas que tratam da produção de fala bilíngue e nos estudos sobre percepção e produção de sons em língua estrangeira.

\section{0 que é bilinguismo/multilinguismo?}

Os termos 'bilinguismo' e 'multilinguismo' são usados, respectivamente, para se referir àqueles indivíduos que são capazes de utilizar duas ou mais línguas. Esses termos não são sinônimos e um grande número de pesquisas trata das diferenças entre as experiências de adquirir e usar duas ou mais de duas línguas (ver, por exemplo, CENOZ; JESSNER, 2000; HERDINA; JESSNER, 2002; CENOZ, 2003; dentre outros). Uma experiência linguística mais diversificada e uma maior diversidade temporal no processo de aquisição, por exemplo, são algumas das principais diferenças, apontadas na literatura, 
entre os processos de aprendizagem de uma terceira ou uma quarta língua, em comparação com a aquisição de uma segunda língua. Neste artigo, entretanto, por razões de escopo, não damos prioridade ao tratamento dessas diferenças, sendo os termos 'bilinguismo' e 'multilinguismo' empregados como sinônimos.

O que caracteriza o domínio de duas ou mais línguas pelo mesmo indivíduo, entretanto, não é fácil de se estabelecer, pois a experiência bilíngue é única. A quantidade e a qualidade da exposição, bem como as oportunidades de uso das línguas, variam enormemente entre os indivíduos, o que torna o bilinguismo um processo dinâmico e complexo. Sabe-se, entretanto, que os bilíngues possuem um tipo de conhecimento e de uso de linguagem que difere do que caracteriza o conhecimento e uso da linguagem dos monolíngues. Por essa razão, no lugar de uma concepção mais restrita de bilinguismo, segundo a qual somente os indivíduos que possuem domínio semelhante a um falante "nativo" nas suas duas ou mais línguas podem ser considerados bilíngues (SAER, 1923), os estudos têm dado lugar a uma definição mais ampla, inclusiva e atual (GROSJEAN, 1998; VAID, 2002; COOK, 2003), que considera o bilíngue como o indivíduo que é capaz de funcionar, em alguma medida, em mais de uma língua. Ou seja, a definição idealizada de bilinguismo, na qual se espera que a pessoa seja capaz de compreender, falar, ler e escrever com perfeição em todas as suas línguas, tem cedido espaço à visão de que os bilíngues possuem diferentes graus de competência nos seus sistemas linguísticos, pois as pessoas adquirem e usam cada uma de suas línguas com diferentes propósitos, em contextos distintos e ao se comunicarem com interlocutores diferentes (GROSJEAN, 1998). Essa experiência linguística única faz com que os bilíngues adquiram diferentes graus de competência nas línguas que usam e muitas vezes possuam um idioma dominante, no qual se sentem mais confortáveis em determinados contextos. Nesse sentido, o domínio de uma língua não é uma aptidão imutável e a manutenção de cada uma das línguas do bilíngue vai depender do contato que ele tem com elas, das condições de uso e da necessidade individual de cada indivíduo.

Com base nessa definição de bilinguismo, apresentamos, nas seções que seguem, exemplos de investigações conduzidas em nosso laboratório, que ressaltarão a premissa de interdisciplinaridade que guia as pesquisas do nosso grupo de pesquisa.

\section{Interação entre Linguística e Psicologia nos estudos sobre o acesso lexical bilíngue}

Estudos psicolinguísticos sobre o acesso lexical bilíngue, uma das linhas de pesquisa que desenvolvemos no LABICO, são um exemplo da importância da interdisciplinaridade na investigação empírica. Em particular, o rigoroso controle metodológico dos estudos sobre acesso lexical bilíngue, explicados mais detalhadamente abaixo, está fortemente relacionado ao controle linguístico dos estímulos que utilizamos nas investigações. Podemos resumir a interação entre a Linguística e a Psicologia nos estudos sobre acesso lexical em duas funções principais: (i) Manipulação de variáveis independentes de interesse de pesquisa, e (ii) Controle de variáveis intervenientes - ambas com papéis cruciais no desenvolvimento de pesquisas empíricas. A interlocução/ colaboração entre essas áreas será exemplificada a seguir, à medida em que apresentamos um panorama geral das pesquisas sobre acesso lexical.

Uma questão fundamental sobre o acesso lexical bilíngue que vem sendo estudada nos últimos 30 anos diz respeito a se palavras de ambas as línguas do bilíngue são consideradas durante esse processo, ou se o bilíngue pode efetivamente 'desligar' a língua que não é relevante para o contexto ${ }^{1}$. $\mathrm{Na}$

${ }^{1}$ Uma revisão dos trabalhos nacionais sobre o acesso lexical bilingue, como os de Billig (2014); Blank (2013); Fonseca (2015); Medeiros et al. (2014); Soto e França (2008) foge do escopo do presente artigo, pois não tratam da mesma pergunta de pesquisa abordada aqui. 
primeira opção, portanto, o acesso lexical bilíngue seria não-seletivo, ou seja, as duas (ou mais) línguas seriam consideradas no processamento e, na segunda, esse acesso seria seletivo, pois somente a língua alvo seria considerada. Estudos que examinam se itens de diferentes línguas são ativados durante o acesso lexical geralmente utilizam palavras cognatas entre as línguas dos bilíngues, ou seja, palavras de alta semelhança ortográfica e que possuem o mesmo significado entre duas línguas (por exemplo, piano ou ator-actor em português e inglês). Pesquisadores utilizam esse tipo de palavras para determinar se falantes bilíngues leem tais palavras de forma diferente de como leem palavras que compartilham apenas uma tradução com a outra língua (como, por exemplo, lápis-pencil em português e inglês). Se diferenças em tempo de resposta são observadas entre cognatas e controles, elas são provavelmente originadas pela co-ativação de representações sobrepostas nas duas línguas, comparadas a uma língua só. Portanto, a ausência dessas diferenças apoia a perspectiva de acesso lexical seletivo; por outro lado, diferenças em tempo de reação entre palavras teste e controles são tomadas como evidência em favor do acesso lexical não seletivo.

Uma revisão de pesquisas realizadas sobre o acesso lexical bilíngue (VAN ASSCHE; DUYCK; HARTSUIKER, 2012) favorece a hipótese da nãoseletividade. Em um dos primeiros estudos a corroborar tal hipótese, Caramazza e Brones (1979) testaram bilíngues de espanhol e inglês em uma tarefa de decisão lexical na segunda língua dos participantes. Os resultados mostraram que os participantes reconheceram as palavras cognatas mais rapidamente do que as correspondentes não-cognatas. Vários estudos subsequentes replicaram esse efeito de facilitação cognata na L2 em estudos de processamento de palavras (BIJELJAC-BABIC; BIARDEAU; GRAINGER, 1997; GOLLAN; FOSTER; FROST, 1997; DIJKSTRA; GRAINGER; VAN HEUVEN; 1998; DIJKSTRA; GRAINGER; VAN HEUVEN, 1999; SCHWARTZ; ARÊAS DA LUZ FONTES, 2008). Outros, por sua vez, observaram o mesmo efeito quando os bilíngues faziam a tarefa de decisão lexical em sua língua nativa e dominante (L1; por exemplo, VAN HELL; DIJKSTRA, 2002). Há ainda evidência do acúmulo desse efeito quando testado com mais de duas línguas, em indivíduos trilíngues (LEMHÖFER; DIJKSTRA, 2004). Este efeito de facilitação cognata é previsto pelo Bilingual Interactive Activation + Model (BIA+, DIJKSTRA; VAN HEUVEN, 2002) e é atribuído ao fato de que uma palavra cognata na L2 também ativa a representação lexical na L1, que está, a um certo nível, mapeado à mesma representação semântica (DIJKSTRA; VAN HEUVEN, 2002). A co-ativação linguística dessas representações acelera o reconhecimento de palavras cognatas em comparação às não cognatas. A maioria dos estudos sobre acesso lexical bilíngue envolve indivíduos cujas duas línguas têm o mesmo sistema de escrita, no caso, o alfabeto romano. No entanto, talvez as evidências mais convincentes a favor da não-seletividade do acesso lexical bilíngue sejam de estudos com falantes de línguas com diferentes sistemas de escrita, como o coreano e o inglês (MOON; JIANG 2012).

É importante ressaltar, porém, que nem todos os estudos encontraram evidência de não-seletividade do acesso lexical bilíngue (CARAMAZZA; BRONES, 1979; MACNAMARA; KUSHNIR, 1971; SOARES; GROSJEAN, 1984). No entanto, a grande maioria dos estudos aponta para a hipótese da nãoseletividade (ver VAN ASSCHE; DUYCK; HARTSUIKER, 2012).

Uma possível explicação para tal diferença de resultados inicialmente obtidos no estudo do acesso lexical bilíngue está relacionada justamente ao papel da Linguística em estudos desse tipo. Quando pesquisadores selecionam as palavras que servirão de estímulos nos seus estudos, há uma série de critérios linguísticos que devem ser levados em conta. Por exemplo, qual é o critério para que uma palavra seja considerada cognata ou não? Quando considerada cognata, consideramos aspectos fonológicos, ortográficos ou ambos das palavras nas duas línguas? Para abordar o problema gerado pela primeira pergunta, existem ferramentas que calculam o grau de semelhança 
ortográfica entre duas palavras (VAN ORDEN, 1987). Se o pesquisador desejar também controlar a semelhança fonológica entre elas, fato que Schwartz; Kroll; Diaz (2007) demonstraram influenciar o reconhecimento de palavras em tarefas de acesso lexical, precisará lançar mão de outra ferramenta que possibilita tal cálculo (http://clearpond.northwestern.edu/). No processo de seleção de estímulos para o experimento, o pesquisador deve ainda cuidar para que sua lista de palavras tenha um controle sintático. Por exemplo, palavras concretas são reconhecidas mais rapidamente do que palavras abstratas, assim como verbos de ação são reconhecidos mais rapidamente que verbos de ligação. Ainda, palavras polissêmicas são processadas com maior rapidez, enquanto as homônimas levam mais tempo. 0 pesquisador deve optar, então, por trabalhar com números iguais de cada tipo de palavra, ou apenas com um deles, pois uma falta de controle nesse sentido pode influenciar os resultados da pesquisa.

A interdisciplinaridade e a importância da Linguística nos estudos sobre o acesso lexical bilíngue fica ainda mais evidente nos estudos de processamento de frases. Uma crítica aos estudos de reconhecimento de palavras, como os citados até então, é de que lhes falta validade ecológica, pois raramente lemos palavras isoladamente, sem o contexto de uma frase. Para que os estudos de acesso lexical sejam mais próximos à realidade, pesquisadores começaram a investigar o acesso lexical bilíngue em contexto, durante a leitura de frases. A principal hipótese testada por esses estudos é se o contexto da frase, que indica ao leitor a língua alvo para a tarefa, pode eliminar a co-ativação entre as línguas, evidenciando então seletividade do acesso lexical em frases.

Schwartz e Kroll (2006) testaram o efeito de palavras cognatas na leitura de frases em L2 com bilíngues de espanhol-inglês. Na tarefa de apresentação visual serial rápida utilizada no estudo, as palavras das frases eram apresentadas uma a uma na tela do computador e os participantes tinham que nomear a palavra alvo que aparecia sempre em vermelho. As palavras alvo de interesse eram, em uma das condições do estudo, cognatas, e as frases podiam ter baixa ou alta taxa de informação semântica (low ou high semantic constrain). No que tange ao efeito de facilitação cognata, este foi observado apenas na condição em que as frases continham pouca informação semântica (low constrain). Ou seja, quando a frase é rica em informação semântica, ela pode atenuar os efeitos de co-ativação das línguas durante a leitura bilíngue.

O estudo de Duyck, van Assche, Drieghe e Hartsuiker (2007) utilizou o método de rastreamento ocular para investigar o curso de tempo do efeito de co-ativação linguística em um grupo de bilíngues de holandês-inglês numa tarefa de leitura de frases na L2. O método de rastreamento ocular possui vantagens importantes, comparado a tarefas como a apresentação visual serial rápida, porque oferece a maneira mais natural de operacionalizar a leitura para um experimento, pois não há necessidade de que o participante realize uma tarefa, que responda a algum estímulo - basta que leia. No estudo de Duyck et al. (2007), os bilíngues leram frases com pouca informação semântica que continham uma palavra cognata ou uma palavra controle. As frases nas duas condições eram as mesmas, apenas a palavra alvo, cognata ou controle, era diferente (por exemplo, Hilda bought a new RING-COAT and showed it to everyone; ring é cognata; coat é controle). Duyck et al. (2007) observaram um efeito de facilitação cognata em medidas de leitura iniciais e tardias, mas apenas para palavras cognatas idênticas (por exemplo, ring-ring, em holandês-inglês), em contraste com as não idênticas (por exemplo, schipship, em holandês-inglês). Os autores sugerem que estes resultados indicam que quando a sobreposição interlinguística da ortografia das palavras não foi completa, como no caso das cognatas não idênticas, o efeito de facilitação cognata não foi forte o suficiente para ser observado em frases. Isso mostra que a quantidade de co-ativação linguística observada no acesso lexical 
bilíngue depende também da similaridade entre as traduções das palavras nas duas línguas. Além disso, os resultados do rastreamento ocular apontam que a co-ativação linguística no léxico bilíngue responsável pelo efeito de facilitação cognata ocorre em fase inicial do processo de reconhecimento de palavras, porque este foi observado na medida de primeiras fixações (first fixations) e permaneceu presente em medidas mais tardias. Efeitos semelhantes utilizando a metodologia de rastreamento ocular foram encontrados também em Libben e Titone (2009) e Van Assche, Drieghe, Duyck, Welvaert e Hartsuiker (2011).

Pesquisas ainda mais recentes investigaram questões relacionadas ao acesso lexical bilíngue durante a leitura, incluindo o possível impacto que fatores linguísticos e cognitivos podem ter sobre o processo de leitura bilíngue. Gullifer, Kroll e Dussias (2013), por exemplo, demonstraram que o efeito de facilitação cognata persiste mesmo quando os bilíngues fazem codeswitching, alternando a língua requerida para processamento, entre uma frase e outra. Van Assche, Duyck e Brysbaert (2013) apresentaram evidência de que o processamento de substantivos difere do de verbos. Além disso, Pivneva, Mercier e Titone (2014) mostraram que o maior controle executivo, e não a proficiência, reduz efeitos de co-ativação linguística em termos de interferência causada por homógrafos interlinguísticos. Em contraste, a maior proficiência, e não o controle executivo, reduziu efeitos de co-ativação linguística em termos de efeitos de facilitação cognata.

Baseando-nos nos estudos sobre acesso lexical revisados até aqui, podese concluir que a mera presença de um contexto sentencial não é suficiente para eliminar completamente efeitos que demonstram a não-seletividade do acesso lexical bilíngue, apesar de haver fatores que modulam o grau de co-ativação das línguas.

Conforme mencionado anteriormente, estudos sobre o acesso lexical bilíngue no processamento de frases evidenciam ainda mais a importância da colaboração com a Linguística. Primeiramente, os estudos apresentados fazem uso de frases com baixa ou alta taxa de informação semântica (low ou high constrain). Que critérios são usados pelos pesquisadores para o desenvolvimento de tais frases? Ou seja, o que constitui baixa ou alta taxa de informação semântica? A ideia de uma frase com alta taxa de informação semântica é a de que ela seja direcionada a um certo sentido, que o leitor consiga prever o que irá encontrar durante a leitura. Já uma frase com baixa taxa de informação semântica é uma frase mais neutra, com menos direcionamento a um certo sentido - até um certo ponto da frase existem possíveis interpretações. O leitor não consegue prever o que vem a seguir. O sucesso dos experimentos depende diretamente da manipulação desses tipos de contexto. Portanto, pesquisadores conduzem testes pilotos em que participantes de pesquisa avaliam o grau de informação semântica das frases. No entanto, não apenas a informação semântica de uma frase auxilia o leitor a prever o que vem a seguir. A informação sintática é essencial na construção do que o leitor prevê como possível ou não em uma frase. Por exemplo, no inglês, espera-se que o adjetivo venha sempre antes do substantivo, e se essa regra é violada a leitura da frase é comprometida. Faz-se extremamente importante, então, que os pesquisadores controlem os aspectos sintáticos das frases que elaboram para seus experimentos. Por exemplo, que tipo de sujeito as frases terão (simples, composto, indeterminado, inexistente), e de que maneira eles se comportam (agente, paciente), se as frases serão em voz ativa ou passiva, se conterão orações subordinadas ou não. É importante também que as frases não possuam ambiguidade sintática, pois essas são processadas com maior dificuldade. 0 cuidado linguístico necessário para a elaboração tanto das frases para estudos de leitura, como para as listas de estímulos nos estudos de reconhecimento de palavras, é o que permite que as comparações empíricas tenham alguma validade. Caso não houvesse esse controle rígido de aspectos linguísticos, os estudos de acesso lexical bilíngue, 
assim como qualquer estudo da Psicolinguística, não teriam o poder de estabelecer relações de causa e efeito entre variáveis.

Esperamos que, com mais este exemplo da importância de estudos interdisciplinares, consigamos estabelecer um diálogo maior com outras áreas de pesquisa, como a Psicologia, a Linguística Aplicada, as Ciências Cognitivas e Linguística Computacional, o que certamente só vem a contribuir para que as pesquisas sobre bilinguismo e multilinguismo na Psicolinguística cresçam cada vez mais.

\section{Interação entre Psicolinguística, Ciências Cognitivas e Neurociências nos estudos sobre produção de fala bilíngue}

As pesquisas sobre o processo de produção de fala bilíngue têm tentado explicar pelo menos dois aspectos distintos: (i) a comunicação fluente em apenas uma das línguas, embora a ativação que se propaga do nível conceitual ao lexical atinja ambas as línguas, isto é, palavras na L1 e na L2 são ativadas; e (ii) as interferências que ocorrem entre as línguas no momento da comunicação, através de empréstimos linguísticos, invasões lexicais, codeswitching, etc. A partir dessas constatações, os estudos sobre a produção de fala em bilíngues podem ser agrupados em torno de cinco hipóteses com relação ao processo de seleção lexical: (i) no nível conceitual; (ii) específica na língua-alvo; (iii) por competição (ou não específica na língua); (iv) por controle inibitório; e (v) sem competição, por ativação limitada e seleção de resposta. Tais hipóteses foram surgindo a partir de evidências de estudos, inicialmente desenvolvidos dentro do paradigma de interferência desenhopalavra e, posteriormente, com os paradigmas de monitoramento de fonemas e de troca de línguas, os quais possibilitam avaliar o comportamento dos participantes a partir de medidas de tempo de reação e acurácia das respostas. Entretanto, mais recentemente, os pesquisadores têm buscado interagir com as Ciências Cognitivas e Neurociências, através do uso de recursos como exames de ressonância magnética funcional (fMRI) e eletroencefalograma (EEG) para melhor avaliar o locus do processo de produção de fala no cérebro bilíngue e, com isso, complementar as explicações baseadas no comportamento bilíngue.

De acordo com a hipótese de seleção no nível conceitual, a língua-alvo da produção de fala é definida no momento em que ocorre o planejamento da mensagem pré-verbal, e isso afeta o nível de ativação das línguas, o qual deve ser maior na língua-alvo (DE BOT, 1992; POULISSE; BONGAERTS, 1994; LA HEIJ, 2005). Mas essa hipótese não consegue explicar os casos de interferências entre as línguas, mencionado anteriormente, o que demonstra que a definição da língua no nível conceitual não consegue impedir que palavras na língua nãoalvo sejam intensamente ativadas de maneira que sejam equivocadamente selecionadas. Por outro lado, conforme a hipótese de seleção específica na língua, os bilíngues conseguem ignorar a ativação de palavras na língua nãoalvo examinando somente o léxico na língua pretendida (COSTA; CARAMAZZA; 1999; COSTA; ALBAREDA; SANTESTEBAN, 2008; HERMANS, 2000; ROELOFS, 1998). Entretanto, de que maneira o mecanismo de seleção restringe a sua busca ao léxico de uma das línguas, de modo a ignorar a outra, é, ainda, um questionamento pendente a essa hipótese.

Por sua vez, para a hipótese de seleção por competição lexical entre as línguas (não específica na língua) existe uma competição pela seleção, na qual todas as palavras ativadas, tanto na língua materna (L1) como na segunda língua (L2), são candidatas e competem entre si (COLOMÉ, 2001; COSTA, et al., 2003; HERMANS et al., 1998; HOSHINO; THIERRY, 2011; MISRA, et al., 2012). Porém, se todas as palavras ativadas têm potencial para serem selecionadas, de que maneira o mecanismo de seleção garante que a palavra selecionada é a adequada na língua-alvo? A busca por respostas a essa pergunta levou pesquisadores a procurar respaldo nas Ciências Cognitivas, 
especificamente, no que se refere ao mecanismo cognitivo denominado 'controle inibitório'. Esse mecanismo seria encarregado de inibir a ativação de palavras não-alvo, o que potencializaria a ativação da palavra na línguaalvo, facilitando, assim, sua seleção (GREEN, 1998; KROLL, et al., 2008; MISRA et al., 2012; ROELOFS, 1998). Cabe ressaltar que os estudos mais atuais, inclusive, têm utilizado exames de ressonância magnética funcional (fMRI) e eletroencefalograma (EEG) para avaliar com mais detalhe a funcionalidade do mecanismo inibitório. Além disso, parece haver relação entre nível de proficiência bilíngue e grau de dependência do mecanismo inibitório, sendo este mais requisitado nos níveis iniciais de desenvolvimento linguístico (COSTA, 2006).

Por outro lado, há ainda uma hipótese de seleção sem competição, a qual supõe que a seleção é decorrente da ativação limitada ou da seleção de resposta, isto é, cada estímulo gera duas respostas e o bilíngue precisa decidir dentre elas qual é a mais apropriada (FINKBEINER; GOLLAN; CARAMAZZA, 2006). Entretanto, trata-se de uma hipótese ainda em nível especulativo, ou seja, carece de evidências experimentais.

Os diferentes estudos realizados para testar tais hipóteses evidenciaram que diferentes fatores externos e internos podem afetar o processo de produção de fala, quais sejam: o nível de proficiência, o tipo de tarefa, a relação entre as línguas, entre outros. Nos estudos que realizamos, em tarefas de nomeação de desenho na L2 (dentro do paradigma de interferência desenho-palavra) tanto com bilíngues balanceados, português-espanhol e espanhol-português (ORTIZ PREUSS, 2011), como com bilíngues portuguêsespanhol, menos balanceados, aprendizes de L2 (ORTIZ PREUSS; ARÊAS DA LUZ FONTES; FINGER, 2015), chegamos a algumas constatações bastante importantes: (i) no caso dos bilíngues balanceados, os resultados foram compatíveis com a hipótese de que a seleção é específica na língua-alvo; (ii) no caso dos aprendizes, houve resultados favoráveis tanto à competição lexical quanto à seleção específica na língua, dependendo do status cognato das palavras envolvidas; (iii) o status cognato das palavras interfere no processo de lexicalização, sendo que a nomeação de cognatas é mais rápida do que de não-cognatas e falso-cognatas.

É importante destacar que nossos experimentos não puderam avaliar adequadamente a competição lexical, porque o paradigma de interferência desenho-palavra induz a competição, pois os bilíngues devem nomear desenhos numa língua e ignorar as palavras distratoras em outra língua. Assim, alguns pesquisadores buscaram analisar o processo de produção de fala, a partir de outros paradigmas, como monitoramento de fonemas e paradigma de troca de línguas, através dos quais foi possível constatar competição e inibição lexical (COSTA; SANTESTEBAN, 2004; COSTA, et al., 2006; LEE; WILLIAMS, 2001; MEUTER; ALLPORT, 1999; MISRA et al., 2012).

A partir do que foi discutido até aqui, considera-se que propor um modelo que descreva completamente a arquitetura e dinâmica do processo de produção de fala bilíngue constitui uma árdua tarefa, tendo em vista que há vários fatores que podem afetar o nível de ativação linguística (GROSJEAN, 2013), dentre os quais constam: nível de proficiência, similaridade linguística, tipo de estímulo (status cognato), tarefa experimental, etc. Sob essa perspectiva, cabe salientar que o nível de proficiência pode afetar a funcionalidade do mecanismo de seleção, sendo necessário um controle inibitório em iniciantes, mas, no caso de falantes mais proficientes, o mecanismo de seleção específica pode ser mais funcional (COSTA; SANTESTEBAN, 2004; COSTA, 2006; COSTA, et al., 2006).

Com relação à questão da similaridade linguística, nossos estudos envolveram línguas muito próximas (português e espanhol). Com isso, foi possível observar que, nesse contexto, a demanda atencional é maior para evitar interferências entre as línguas (ORTIZ PREUSS, 2014). Um aspecto que merece destaque é o caso das falso-cognatas, que foram as palavras que 
apresentaram o segundo menor tempo de reação e o segundo maior nível de acurácia. Considerando-se que as falso-cognatas geram conflito por terem forma semelhante, mas distinto significado, observa-se que isso pode ser minimizado pela frequência de uso das palavras, pela facilitação da ativação fonológica e também, no caso dos contextos formais de ensino, por serem foco de algum tipo de instrução para chamar a atenção sobre as diferenças de sentido e de uso entre as línguas.

Em outro estudo, ainda em desenvolvimento, sobre percepção e produção de enunciados interrogativos (totais e parciais) em espanhol por aprendizes brasileiros, constatamos a dificuldade de se identificar os pontos em que as curvas melódicas das línguas portuguesa e espanhola se distinguem, principalmente, na produção, sendo frequente a articulação baseada na entonação da L1. Em vista disso, consideramos que o foco atencional e as intervenções pedagógicas mais explícitas podem facilitar o reconhecimento de padrões entonacionais, pelo menos no caso dessas línguas próximas.

Conforme o exposto, o processo de produção de fala bilíngue é ainda um aspecto do bilinguismo com muitas questões em aberto e que a proximidade linguística não se traduz em facilidade de produção oral, mas sim, aponta novos aspectos a serem considerados na busca pela compreensão de tal processo. Além disso, é preciso ressaltar que essa área de pesquisa não tem sido tão extensivamente estudada, principalmente pelas dificuldades de operacionalização das pesquisas, e pela necessidade de articulação interdisciplinar com as Ciências Cognitivas, a Linguística, a Linguística Aplicada, a Fonologia e a Psicolinguística, por exemplo. O desenvolvimento de pesquisas numa perspectiva interdisciplinar, portanto, torna-se fundamental para se poder descrever com mais detalhe a arquitetura funcional do processo de produção de fala bilíngue, uma vez que possibilita considerar não só as informações comportamentais dos participantes, mas também o funcionamento mental/cerebral subjacente.

\section{Interação entre Fonética, Fonologia e Psicolinguística nos estudos sobre percepção e produção de sons em língua estrangeira (LE)}

Também como exemplo da necessidade de interlocução entre as diversas áreas da Linguística e os estudos psicolinguísticos, discutimos, nesta seção, alguns estudos desenvolvidos por nosso grupo de pesquisa, voltados à área de aquisição fonético-fonológica de L2/LE. Pretendemos, através desta reflexão, incitar a discussão acerca da necessidade de associação dos modelos perceptuais, de inteligibilidade e de produção de sons, a perspectivas que abarquem todo o conhecimento teórico a respeito de processamento linguístico da língua adicional.

No que diz respeito a modelos perceptuais, dois são os considerados mais representativos na área de aquisição fonético-fonológica de L2: o Speech Learning Model (FLEGE, 1995, 2003), e o Perceptual Assimilation Model-L2 (BEST, 1995; BEST; TYLER, 2007). Ambos os modelos se mostram distintos no que diz respeito ao primitivo tomado como base de análise; de fato, o primeiro tem uma forte influência da abordagem psicoacústica de percepção da fala (cf. OHALA, 1986), e o segundo é proposto a partir de uma abordagem realista direta (cf. GIBSON, 1986, FOWLER, 1996), que assume o gesto articulatório (cf. BROWMAN; GOLDSTEIN, 1992) como unidade basilar. Apesar dessas diferenças referentes à concepção do primitivo da percepção, os dois modelos podem ser aproximados no que diz respeito a diversas premissas, pois (i) rejeitam a noção de um período crítico para o desenvolvimento fonético-fonológico de segunda língua; (ii) reconhecem o caráter fundamental da experiência linguística e da exposição ao input; (iii) consideram que a percepção dos sons da L2 se estabelece a partir da capacidade perceptual em L1.

Mais do que apontar os pontos divergentes ou consonantes de ambas as propostas, pretendemos, aqui, levantar os aspectos de ambos os modelos 
que chamam a atenção para a necessidade de uma maior interlocução com a noção de processamento linguístico. Frente a esse objetivo, iniciemos mencionando alguns achados de estudos desenvolvidos em nosso laboratório, que chamam a atenção para tal interlocução. Diversos estudos empíricos por nós conduzidos (cf. ALVES; ZIMMER, 2015; SCHWARTZHAUPT; ALVES; ARÊAS DA LUZ FONTES, 2015) têm demonstrado que a percepção de aspectos fônicos de L2 implica atentar para aspectos acústicos/articulatórios que se mostram prioritários em um determinado sistema. Conforme apontado em Schwartzhaupt, Alves e Arêas da Luz Fontes (2015), no caso das plosivas iniciais, a presença/ausência da aspiração mostra-se fundamental para as distinções entre segmentos surdos (/p, t, k/) e sonoros (/b, d, g/) entre ouvintes nativos do inglês, mas não entre ouvintes do português. Em nossa língua, pistas adicionais, tais como o pré-vozeamento, a força da explosão e a transição de F0 entre o segmento consonantal e a vogal, ao agirem em conjunto, conseguem dar conta desta distinção funcional na L2. Perceber a distinção entre plosivas surdas e sonoras iniciais do inglês, portanto, implica atentar e 'sintonizar' a percepção à aspiração, que pode ser tomada como redundante na língua materna desses aprendizes.

A partir da reflexão acerca da necessidade de 'sintonizar' a percepção nesse detalhe, emergem questões que não são explicitamente contempladas por nenhum dos dois modelos supracitados. Estas questões dizem respeito, sobretudo, à noção da atenção ao input e à capacidade de processamento deste input de modo a "focalizar" o detalhe que realmente interessa. Ainda que sejam feitas ligeiras menções ao papel importante da atenção nos textos fundadores de ambos os modelos, não encontramos, nas duas propostas teóricas, definições claras do que seria atentar para um aspecto acústico (cf. a teoria de Flege) ou gestual (cf. o modelo de Best; Tyler) primordial, frente a outros aspectos não tão importantes para a língua-alvo. Tampouco são fornecidas informações acerca de como se daria esta "troca" de foco, que implicaria o abandono daquelas pistas prioritárias na L1 para a focalização naquelas da L2. Frente a esse quadro, consideramos que uma reflexão maior acerca do processamento linguístico, referente ao foco de atenção a um input rico de aspectos a serem atentados, colaboraria para esses modelos.

Uma outra questão bastante importante, a respeito da qual ambos os modelos carecem de maiores explicações, diz respeito aos efeitos da transferência grafo-fônico-fonológica (cf. ZIMMER; SILVEIRA; ALVES, 2009) na percepção (e consequente produção) dos sons em L2. Sabemos que, em sistemas cuja relação entre ortografia e produção de sons é mais opaca, tal como o inglês, a percepção se faz mais difícil para aprendizes que tenham, como L1, o português ou o espanhol, que apresentam uma relação grafofônico-fonológica mais rasa. Os aprendizes tendem a transferir os padrões da L1 para suas representações fônicas das palavras-alvo, o que pode acarretar em severas dificuldades no reconhecimento de tais itens lexicais. Apesar de a forma grafada exercer papel importante para a percepção, nenhum dos dois modelos perceptuais supracitados, entretanto, faz menção explícita a esse fato, uma vez que se restringem à percepção da cadeia sonora de forma desvinculada de qualquer efeito gráfico. Considerando-se o efeito exercido pela forma grafada ao "moldar" a percepção da L2, julgamos que a reflexão acerca dos efeitos do input grafado se mostrará viável a partir de pesquisas conjuntas que abarquem, também como construto teórico de base, a noção de processamento linguístico.

Ao termos discutido os principais modelos de percepção fonéticofonológica em L2, julgamos necessário trazer à tona, também, um outro construto da área: o conceito de inteligibilidade. Ao discutirmos esse construto, iniciamos mencionando que ainda não há, entre os pesquisadores, um consenso no que diz respeito à definição e à caracterização de tal termo. Em recente trabalho, Derwing e Munro (2015, p. 15-16) caracterizam inteligibilidade como "a extensão a qual um ouvinte intende o significado 
pretendido por um falante de L2", ou, em outras palavras, como o "grau de entendimento, por parte do ouvinte, da mensagem pretendida pelo falante" (ibid.).

Ainda que as definições supracitadas possam, a uma primeira vista, vir a ser julgadas apropriadas, julgamos que as referidas definições também trazem à voga um amplo debate que carece, sobretudo, da interlocução com estudiosos da relação entre linguagem e cognição. Em primeiro lugar, e de modo bastante importante, é preciso discutir o que se entende por "entender", em termos de tarefa cognitiva. Mais do que isso, uma vez que ambas as definições se referem ao entendimento de uma mensagem "pretendida" pelo falante, outras questões vêm a ser necessárias: como podemos vir a saber qual era a mensagem efetivamente pretendida pelo falante? Aquilo que é "entendido" (lembrando-nos de que tal termo, por si só, já carece de uma definição) de forma diferente do previamente pretendido pelo emissor implica, necessariamente, fracasso ou falha na comunicação? De que forma podemos verificar tal entendimento empiricamente, e, mais do que isso, como testar se há uma consonância entre o conteúdo emitido e o supostamente entendido, caso tal consonância seja realmente necessária?

Embora respostas definitivas para esses questionamentos estejam naturalmente longe de serem esgotadas, acreditamos que alguns caminhos podem ser lançados, através de, sobretudo, três aspectos: (i) é necessário uma maior compreensão acerca da caracterização do que significa "entender", e, nesse sentido, as Ciências Cognitivas podem prestar sua contribuição para o debate; (ii) uma vez que a inteligibilidade da fala constitui uma propriedade que passa, necessariamente, pela percepção de sons da língua estrangeira, julgamos necessário conciliar modelos de percepção e inteligibilidade em L2; tal aproximação teórica passa, necessariamente, pela interlocução entre pesquisadores voltados ao processamento cognitivo da linguagem, na Psicolinguística; (iii) ainda que, sob a caracterização de Derwing e
Munro (2015), inteligibilidade seja constituída como uma propriedade sobretudo relacionada ao grau de acento em língua estrangeira, é preciso investigar, também, o papel da informação contextual acerca do conteúdo daquilo que está sendo dito, da experiência do ouvinte com estrangeiros de determinada língua materna, bem como do conhecimento prévio, por parte do ouvinte, acerca daquilo que é dito. Com relação a este ponto, estudos como o de Schwartzhaupt (2015), desenvolvido no LABICO, evidenciam o papel fundamental não somente do grau de acento em língua estrangeira, mas, também, da informação contextual e da experiência do ouvinte com os itens lexicais utilizados nas elocuções. Trabalhos como o citado acima, que se voltam para variáveis como frequência de item, grau de experiência do ouvinte com a L1 do estrangeiro, presença da informação contextual, grau de acento e relação entre percepção de sons isolados e inteligibilidade, além de uma série de outros aspectos, se fazem possíveis somente ao conciliarmos referenciais da área de aquisição fonético-fonológica, próprios do campo da Fonética e Fonologia, com uma base teórica voltada aos processos cognitivos envolvidos no uso efetivo da L2 advindos dos estudos da Psicolinguística. Essa interlocução, em outras palavras, se mostra fundamental para o entendimento do fenômeno.

Considerando-se os estudos vigentes em aquisição fonético-fonológica de L2, é cada vez mais inegável a relação entre percepção e produção dos sons da L2. Ainda que tal relação possa vir a ser mais ou menos explicitamente reconhecida a partir do modelo perceptual a ser empregado, é inegável que os estudos em produção dos sons, associados ou não a metodologias que se voltem, também, à verificação das capacidades perceptuais do aprendiz, muito nos podem informar sobre processamento em L2. Recentes estudos desenvolvidos em nosso grupo têm demonstrado tais aspectos, a partir da investigação não somente dos efeitos da L1 no estabelecimento do acento em L2, mas, também, no estudo do modo como a L2 pode afetar a própria 
língua materna do aprendiz. Kupske (2016) estudou a produção, por parte de brasileiros residentes em Londres, das plosivas iniciais /p, t, k/ do português, de modo a verificar os efeitos do atrito linguístico na produção em L1. O autor organizou seus participantes em três grupos, em função do tempo de residência dos informantes brasileiros no país de língua inglesa. Testes estatísticos demonstraram diferenças significativas entre os grupos, de modo a evidenciar que, quanto maior o tempo de residência no estrangeiro, mais atritada era a produção em L1 desses participantes.

Nessa mesma linha, também no LABICO, Pereyron e Alves (2015) investigaram a produção em espanhol (L1) e português (L2) das vogais produzidas por participantes argentinos residentes na cidade de Porto Alegre. Os autores demonstraram que, tanto em termos de altura/anterioridade da língua quanto em termos de duração, os segmentos vocálicos dos hispanofalantes residentes no Brasil se mostravam significativamente distintos daqueles produzidos por falantes monolíngues, residentes na Argentina, que compartilhavam o mesmo dialeto de L1 dos participantes do grupo experimental. Tais resultados, além de desafiar a tradicional abordagem unidirecional (L1-L2) da transferência linguística, provêm evidências empíricas para uma aproximação entre pesquisadores, uma vez que o dado fonético-fonológico serve como evidência de que L1 e L2 se desenvolvem em um mesmo espaço cognitivo comum, e não em diferentes "caixinhas" ou "compartimentos" de natureza incomunicável.

Por fim, trazemos à tona, ainda, uma questão que se caracteriza por uma grande interlocução não somente entre foneticistas-fonólogos e psicolinguistas, mas, também, com investigadores voltados a áreas mais aplicadas da linguística: o papel da instrução explícita e o de treinamento perceptual na produção e percepção do sistema de sons da língua-alvo. Ainda que, em princípio, tal questão possa vir a parecer trivial - visto que nossa experiência docente tende, justamente, a reconhecer vários efeitos benéficos de tais práticas - a questão está longe de constituir um consenso teórico entre os pesquisadores da Linguística Aplicada.

Uma das razões para as visões discrepantes a respeito das práticas de instrução explícita e treinamento perceptual tem origem nos modelos perceptuais supracitados. Se, por um lado, os textos basilares do Speech Learning Model não fazem alusão aos efeitos de tais práticas, de modo que tais questões, ainda não rechaçadas, venham a constituir uma questão de processamento linguístico "alheio" ao modelo, por outro lado, modelos como o Perceptual Assimilation Model-L2 advogam a ineficiência de tais práticas, sobretudo se em contextos de LE, para os quais, segundo os proponentes, o modelo não pode ser aplicado. Além disso, sob a visão dicotômica defendida na proposta de Best e Tyler (2007), seu modelo perceptual deve ater-se a contextos de L2, não de LE, uma vez que este último contexto se mostra deficitário em termos de quantidade e qualidade de input.

A caracterização acima parece resolver muito simplesmente questões bastante complexas do ponto de vista do processamento linguístico. Em primeiro lugar, podemos fazer menção, justamente, à dicotomia L2-LE: seria a L2 o lugar em que o processamento do input é indiscutivelmente inevitável, e a LE constituiria um ambiente em que tal processamento seria, necessariamente, impossível? Sob essa linha de raciocínio, então, o processamento do input ocorreria igualitariamente entre todos os que compartilham de um ambiente de L2? Nesse sentido, múltiplas variáveis não estariam sendo envolvidas na questão do processamento da informação linguística? Essas e muitas outras questões, aliadas às descobertas já não tão atuais de que os mecanismos cognitivos que permeiam o processamento de L2 são os mesmos que permeiam a LE, acabam pondo por terra uma solução tão simplesmente dicotômica, trazendo à discussão questões de cunho fundamental como a exposição, a quantidade e o processamento do input, independentemente do contexto em que se encontre o aprendiz. 
Mais do que isso, ainda no que concerne ao modelo de Best e Tyler (2007), é preciso dizer que os fundamentos de um conhecimento de natureza declarativa, como aquele que pode vir a ser propiciado pela instrução explícita, acaba se chocando com as previsões de uma concepção de percepção realista direta, como a defendida no Perceptual Assimilation Model. De fato, de acordo com tal concepção, os objetos do ambiente são percebidos sem intermediários ou mediadores. Caso haja espaço para alguma forma de contribuição ou ação de um conhecimento declarativo, que viesse a interagir com o conhecimento procedural, tal discussão não estaria dentro do escopo do modelo, compreendendo processo cognitivo à parte, que acaba sendo, por muitas vezes, sumariamente desconsiderado, então, pelos foneticistas e fonólogos.

Por sua vez, percebemos que, na proposta do Speech Learning Model, em que o papel da instrução não vem a ser declaradamente descartado, efeitos de treinamento ou de instrução explícita parecem compreender um aspecto extrínseco: parte-se, a nosso ver, da assunção de que tais investigações competem ao 'psicolinguista', e não ao 'foneticista' ou 'fonólogo', seguindose uma visão dicotômica de áreas do conhecimento. Na busca de, justamente, combater essa visão dicotômica entre "o que faz isso" e "o que faz aquilo", uma vez que o desenvolvimento linguístico é, indiscutivelmente, um fenômeno de natureza cognitiva, nosso grupo de pesquisas tem, também, levado a cabo uma série de experimentos que visam a verificar os efeitos da instrução explícita (cf. PEROZZO, 2013) e do treinamento perceptual (cf. ALVES, 2015; RODRIGUES, 2015) tanto na percepção quanto na produção dos sons da L2. Os resultados empíricos desses estudos têm demonstrado efeitos benéficos, de curto e longo prazo, no processo de desenvolvimento do sistema sonoro das línguas-alvo envolvidas. Apesar dos evidentes ganhos empíricos, julgamos que, tão importante quanto apontar os resultados benéficos de tais práticas (o que, em si, já presta uma contribuição com a pedagogia de línguas estrangeiras, trazendo à baila a interação entre o que a princípio poderiam ser consideradas áreas específicas e diferenciadas da Linguística), é a tarefa de refletir teoricamente nos fenômenos cognitivos envolvidos, de modo que se venha a repensar os modelos vigentes de percepção, para que eles sejam discutidos em conjunção com pressupostos que os situem dentro do âmbito cognitivo. Julgamos que esta meta, apesar de poder ser considerada como de longo prazo, deve constituir uma das intenções de todos aqueles que veem a percepção e a produção dos sons como efeitos do processamento linguístico.

Em suma, nesta seção, acreditamos ter apontado uma série de desafios a serem enfrentados pelos pesquisadores que se voltam ao desenvolvimento dos sistemas de sons de línguas adicionais. Tais desafios dizem respeito à necessidade não somente de estabelecermos um elo entre os modelos perceptuais, de inteligibilidade e de produção em L2; diz respeito, também, à necessidade de uma reflexão conjunta entre os modelos fonético-fonológicos supracitados e os construtos teóricos referentes ao processamento linguístico. Essa reflexão, vinda da interlocução que buscamos sempre aprofundar em nosso grupo de investigações, não deve ser considerada como um aspecto adicional, mas, sim, como uma demanda teórico-metodológica necessária para aqueles que se dedicam a essa área de investigação.

\section{Considerações finais}

A partir de uma visão de multilinguismo como um dilema intercultural, cujas características, a nosso ver, são mais bem elucidadas a partir de estudos interdisciplinares, este artigo teve como objetivo exemplificar de que forma o diálogo entre as várias áreas da Linguística e os diferentes campos do conhecimento caracteriza e enriquece os estudos desenvolvidos no âmbito do LABICO/UFRGS. Essa atitude interdisciplinar que caracteriza nossos estudos visa a ampliar o entendimento da natureza do processo de 
aquisição e uso da linguagem por indivíduos multilíngues, obtida a partir de estudos conduzidos em áreas específicas, e fomenta o debate sobre definições, teorias e metodologias que possam elucidar esse fenômeno tão complexo que é o multilinguismo.

\section{Referências}

ALVES, Ubiratã K. Adquisición fonético-fonológica del inglés por argentinos y brasileros: efectos del entrenamiento perceptivo. Trabalho apresentado nas IV Jornadas Internacionales de Fonética y Fonología. Presidencia Roque Saenz Pe-a, Argentina, 2015. ALVES, Ubiratã K.; ZIMMER, Márcia C. Percepção e produção dos padrões de VOT do inglês por aprendizes brasileiros: o papel de múltiplas pistas acústicas sob uma perspectiva dinâmica. Alfa Revista de Linguística, v. 59, n.1, p. 157-180, 2015. http:// dx.doi.org/10.1590/1981-5794-1502-7

BEST, Catherine T. A direct realist view of cross-language speech perception. In: STRANGE, Winifred (ed.). Speech perception and linguistic experience: issues in crosslanguage research. Timonuim, MD: York Press, 1995, p. 171-204.

BEST, Catherine T.; TYLER, Michael D. Nonnative and second-language speech perception: commonalities and complementarities. In: BOHN, Ocke S.; MUNRO, Murray J. Language Experience in Second Language Speech Learning: In honor of James Emil Flege. Amsterdam/Philadelphia: John Benjamins Publishing Company, 2007, p. 13-34. http://dx.doi.org/10.1075/llt.17.07bes

BIJELJAC-BABIC, Ranka; BIARDEAU, Agnes; GRAINGER, Jonathan. Masked orthographic priming in bilingual word recognition. Memory and Cognition, v. 25, p. 447-457, 1997. http://dx.doi.org/10.3758/BF03201121

BILLIG, Johanna D. Impacto do bilinguismo nas redes de atenção, no acesso lexical e na memória de trabalho em adultos e idosos. 2014. 166 fls. Tese (Doutorado em Letras) Universidade Federal do Rio Grande do Sul, 2014.

BLANK, Cintia A. A influência grafo-fônico-fonológica na produção oral e no processamento de priming em multilíngues: uma perspectiva dinâmica. 2013. 225 fls. Tese (Doutorado em Letras) - Universidade Católica de Pelotas, 2013.

BROWMAN, Cathernine; GOLDSTEIN, Louis. Articulatory Phonology: an overview. Phonetica, 49, p. 155-180, 1992. http://dx.doi.org/10.1159/000261913
CARAMAZZA, Alfonso; BRONES, Isabel. Lexical access in bilinguals. Bulletin of the Psychonomic Society, v. 13, n. 4, p. 212-214, 1979. http://dx.doi.org/10.3758/BF03335062

CENOZ, Jasone. The additive effect of bilingualism on third language acquisition: A review. International Journal of Bilingualism, v.7, p. 71-87, 2003. http://dx.doi.org/ $10.1177 / 13670069030070010501$

CENOZ, Jasone; JESSNER, Ulrike. (Eds). English in Europe: The acquisition of a third language. Clevedon: Multilingual Matters, 2000.

COLOMÉ, Àngels. Lexical Activation in bilinguals' speech production: language-specific or language-independent? Journal of Memory and Language, v. 45, p. 721-736. 2001. http://dx.doi.org/10.1006/jmla.2001.2793

COOK, Vivian. The effects of the second language on the first. London: Multilingual Matters, 2003.

COSTA. Albert; ALBAREDA, Bárbara; SANTESTEBAN, Mikel. Assessing the presence of lexical competition across languages: Evidence from the Stroop task. Bilingualism: Language and Cognition, Cambridge, v. 11, n. 1. p. 121-131. 2008.

COSTA, Albert. Speech Production in Bilinguals. In: BHATIA, Tej K.; RITCHIE, William C. (Ed.). The Handbook of bilingualism. Oxford: Blackwell Publishing, 2006. p. 201-223.

COSTA, Albert; LA HEIJ, Wido; NAVARRETE, Eduardo. The dynamics of bilingual lexical access. Bilingualism: Language and Cognition, Cambridge, v. 9, n. 2. p. 137-151, 2006.

COSTA, Albert; SANTESTEBAN, Mikel. Lexical access in bilingual speech production Evidence from language switching in highly proficient bilinguals and L2 learners. Journal of Memory and Language, v. 50, p. 491-511. 2004. http://dx.doi.org/10.1016/j. jml.2004.02.002

COSTA, Albert; CARAMAZZA, Alfonso. Is lexical selection in bilingual speech production language-specific? Further evidence from Spanish-English and English-Spanish bilinguals. Bilingualism: Language and Cognition, Cambridge, v. 2, n. 3, p. 231-244, 1999.

DE BOT, Kees. A bilingual production model: Levelt's speaking' model adapted. Applied Linguistics, Oxford, v. 13, n. 1, p. 1-24, 1992.

DERWING, Tracey M.; MUNRO, Murray J. The interface of teaching and research: What type of L2 pronunciation instruction should learners expect? In: LUCHINI, Pedro Luis; GARCÍA JURADO, María Amalia; ALVES, Ubiratã Kickhöfel (eds.). Fonética y fonología: 
articulación entre enseñanza e investigación. Mar del Plata, Argentina, Universidad Nacional de Mar del Plata, 2015, p. 14-26.

DIJKSTRA, Ton; VAN JAARSVELD, Hank; BRINKE, Ten S. Interlingual homograph recognition: Effects of task demands and language intermixing. Bilingualism, v. 1, n. 1, p. 51-66, 1998. http://dx.doi.org/10.1017/S1366728998000121

DIJKSTRA, Ton; GRAINGER, Jonathan; VAN HEUVEN, Walter. Recognition of cognates and interlingual homographs: the neglected role of phonology. Journal of Memory and Language, v. 41, p. 496-518, 1999. http://dx.doi.org/10.1006/jmla.1999.2654

DIJKSTRA, Ton; VAN HEUVEN, Walter. The architecture of the bilingual word recognition system: From identification to decision. Bilingualism, v. 5, n. 3, 2002.

DUYCK, Wouter; VAN ASSCHE, Eva; DRIEGHE, Denis; HARTSUIKER, Robert J. Visual word recognition by bilinguals in a sentence context: evidence for nonselective lexical access. Journal of Experimental Psychology: Learning, Memory, and Cognition, v. 33, p. 663-679, 2007. http://dx.doi.org/10.1037/0278-7393.33.4.663

FINKBEINER, Matthew; GOLLAN, Tamar H.; CARAMAZZA, Alfonso. Lexical access in bilingual speakers: What's the (hard) problem? Bilingualism: Language and Cognition. Cambridge, v. 9, n. 2.p. 153-166. 2006.

FLEGE, James E. Second Language Speech Learning: Theory, findings, and problems. In: STRANGE, Winifred (ed.). Speech perception and linguistic experience: Issues in crosslanguage research. Timonium, MD: York Press, 1995, p. 233-277.

Assessing constraints on second-language segmental production and perception. In: SCHILLER, Niels O.; MEYER, Antje S. (eds.). Phonetics and phonology in language comprehension and production: differences and similarities. Berlin, Mouton, 2003, p. 319-361.

FONSECA, Sandro. Bilinguismo bimodal: um estudo sobre o acesso lexical em intérpretes de libras-português. 2015. 101 fls. Dissertação (Mestrado em Letras) - Universidade Federal do Rio Grande do Sul, 2015.

FOWLER, Catherine. Listeners do hear sounds, not tongues. The Journal of the Acoustical Society of America, v. 99, n. 3, p. 1730-1741, 1996. http://dx.doi.org/10.1121/1.415237

GIBSON, James J. The ecological approach to visual perception. New York: Psychology Press, 1986.

GOLLAN, Tamar H.; FORSTER, Ken I.; FROST, Ram. Translation priming with different scripts: Masked priming with cognates and noncognates in Hebrew-English bilinguals.
Journal of Experimental Psychology: Learning, Memory, and Cognition, v. 23, n. 5, p. 11-22, 1997.

GOLDSTEIN, Louis; FOWLER, Catherine A. Articulatory Phonology: A Phonology for Public Language Use. In: SCHILLER, Niels O.; MEYER, Antje S. (eds.). Phonetics and Phonology in Language Comprehension and Production. Mouton de Gruyter, 2003, p. 159-207.

GREEN, David W. Mental control of the bilingual lexico-semantic system. Bilingualism: Language and Cognition. Cambridge, v. 1, n. 2, p. 67-81, 1998.

GROSJEAN, François. Speech production. In: GROSJEAN, François; LI, Ping. The psycolinguistics of bilingualism. Oxford: Wiley-Blackwell, 2013. p. 50-69.

. Studying bilinguals: Methodological and conceptual issues. Bilingualism: Language and Cognition, v. 1, p. 131-149, 1998. http://dx.doi.org/10.1017/S1366728998000285

GULLIFER, Jason; KROLL, Judith; DUSSIAS, Paola. When Language Switching has No Apparent Cost: Lexical Access in Sentence Context. Frontiers in Psychology, v. 4, 2013.

HERDINA, Philip; JESSNER, Ulrike. A dynamic model of multilingualism: Perspectives of change in Psycholinguistics, Clevedon: Multilingual Matters, 2002. 182p.

HERMANS, Daan; BONGAERTS, Theo; DE BOT, Kees; SCHREUDER, Rodert. Producing words in a foreign language: can speakers prevent interference from their first language? Bilingualism: Language and Cognition, Cambridge, v. 1, n. 3. p. 213-230. 1998.

HOSHINO, Noriko; THIERRY, Guillaume. Language selection in bilingual word production: electrophysiological evidence for cross-language competition. Brain research, p. 100109. 2011.

KROLL, Judith F.; BOBB, Susan C.; MISRA, Maya; GUO, Taomei. Language selection in bilingual speech: Evidence for inhibitory processes. Acta Psychologica, p. 1-15. 2008.

KUPSKE, Felipe. Imigração, atrito e complexidade: a produção das oclusivas surdas iniciais do inglês e do português por brasileiros residentes em Londres. 2016. 242 fls. Tese (Doutorado em Letras) - Universidade Federal do Rio Grande do Sul, 2016.

LA HEIJ, Wido. Selection processes in monolingual end bilingual lexical access. In: KROLL, Judith F. DE GROOT, Annette M.B. (Ed.). Handbook of bilingualism: Psycholinguistic Approaches. Oxford: Oxford University Press, 2005. p. 289-307.

LEE, Ming-Wei., WILLLIAMS, John N. Lexical access in spoken word production by bilinguals: Evidence from a semantic priming paradigm. Bilingualism: Language and Cognition, Cambridge, v. 4, p. 233-248, 2001. 
LEMHÖFER, Kristin; DIJKSTRA, Ton; MICHEL, Marije C. Three languages, one echo: cognate effects in trilingual word recognition. Language and Cognitive Processes, v. 19, p. 585-611, 2004. http://dx.doi.org/10.1080/01690960444000007

LIBBEN, Maya; TITONE, Debra. Bilingual lexical access in context: Evidence from eye movements during reading. Journal of Experimental Psychology: Learning, Memory, and Cognition, v. 35, n. 2, p. 381-390, 2009. http://dx.doi.org/10.1037/a0014875

MACNAMARA, John; KUSHNIR, Seymour. Linguistic independence of bilinguals: The input switch. Journal of Verbal Learning and Verbal Behavior, v. 10, n. 5, p. 480-487, 1971. http://dx.doi.org/10.1016/S0022-5371(71)80018-X

MEDEIROS, Joyse; WEISSHEIMER, Janaina; FRANÇA, Aniela I.; RIBEIRO, Sidarta. Acesso lexical: uma rota dupla para o português brasileiro. Fórum Linguístico, v. 11, n. 3, p. 278-292, jul./set. 2014. http://dx.doi.org/10.5007/1984

MEUTER, Renata F. I.; ALLPORT, Alan. Bilingual language switching in naming: asymmetrical costs of language selection. Journal of Memory and language, v. 40, n. 1, p. 25-40. 1999. http://dx.doi.org/10.1006/jmla.1998.2602

MIRANDA, Raquel G. Da interdisciplinaridade. In: FAZENDA, Ivani C. A. (Org.). o que é interdisciplinaridade? São Paulo: Cortez, p. 113-124, 2008.

MISRA, Maya; GUO, Taomei; BOBB, Susan C.; KROLL, Judith F. When bilinguals choose a single word to speak: Electrophysiological evidence for inhibition of the native language. Journal of Memory and language, v. 67, n. 1, p. 224-237. 2012. http://dx.doi.org/10.1016/j. jml.2012.05.001

MOON, Jihye; JIANG, Nan. Non-selective lexical access in different-script bilinguals. Bilingualism, v. 15, n. 1, p. 173-180, 2011

OHALA, John J. Speech perception is hearing sounds, not tongues. Journal of the Acoustical Society of America, n. 99, p. 1718-1725, 1996. http://dx.doi.org/10.1121/1.414696

ORTIZ PREUSS, Elena. Similaridade linguística entre português e espanhol: efeitos na produção de fala em L2. Revista (Con)Textos linguísticos, Vitória: PPGEL-UFES, v. 8, n. 10, p. $66-82,2014$

Acesso lexical e produção de fala bilíngue: o processo de seleção linguística. Organon, Porto Alegre (UFRGS), série 51, v. 26, p. 81-101, 2011.

ORTIZ PREUSS, Elena; ARÊAS DA LUZ FONTES, Ana B.; FINGER, Ingrid. Efeito cognato no processo de lexicalização bilíngue. Letras de Hoje, Porto Alegre, v. 50, n. 1. p. 73-83, 2015 .
PEREYRON, Letícia; ALVES, Ubiratã K. A aquisição do sistema vocálico do português por falantes da variedade rio-platense de espanhol: uma discussão sobre a bidirecionalidade da transferência vocálica. Trabalho apresentado no II Encontro Intermediário do GT de Fonética e Fonologia da ANPOLL. Uberlândia: Universidade Federal de Uberlândia, 2015.

PEROZZO, Reiner V. Percepção de oclusivas não vozeadas sem soltura audível em codas finais do inglês (L2) por brasileiros: o papel da instrução explícita e do contexto fonéticofonológico. 2013. 193f. Dissertação (Mestrado em Letras) - Universidade Federal do Rio Grande do Sul, Porto Alegre-RS, 2013.

PEROZZO, Reiner V.; ALVES, Ubiratã K. Uma discussão acerca da viabilidade de aplicação do Perceptual Assimilation Model-L2 a contextos de LE: questões de pesquisa e desafios metodológicos. Trabalho apresentado no II Encontro Intermediário do GT de Fonética e Fonologia da ANPOLL. Uberlândia: Universidade Federal de Uberlândia, 2015

PIVNEVA, Irina; MERCIER, Julie; TITONE, Debra. Executive control modulates crosslanguage lexical activation during L2 reading: Evidence from eye movements. Journal of Experimental Psychology: Learning, Memory, and Cognition, v. 40, n. 3, p. 787-796, 2014. http://dx.doi.org/10.1037/a0035583

POULISSE, Nanda; BONGAERTS, Theo. First language use in second language production Applied Linguistics, n. 15, 1994, p. 36-57. http://dx.doi.org/10.1093/applin/15.1.36

RODRIGUES, Gustavo S. Efeitos do treinamento perceptual na aquisição das oclusivas surdas do inglês por brasileiros. 2015. 97 fls. Trabalho de Conclusão de Curso. Universidade Federal do Rio Grande do Sul, 2015.

ROELOFS, Ardi. Lemma selection without inhibition of languages in bilingual speakers Bilingualism: Language and Cognition, p. 94-95. 1998.

SAER, David. J. The Effects of bilingualism on intelligence. The British Journal of Psychology, v. 14, p. 25-38, 1923.

SCHWARTZ, Ana I.; AREAAS DA LUZ FONTES, Ana B. Cross-language mediated priming: Effects of context and lexical relationship. Bilingualism, v. 11, n. 01, 2008.

SCHWARTZ, Ana I.; KROLL, Judith; DIAZ, Michelle. Reading words in Spanish and English: Mapping orthography to phonology in two languages. Language and Cognitive Processes, v. 22, n. 1, p. 106-129, 2007. http://dx.doi.org/10.1080/01690960500463920

SCHWARTZ, Ana I.; KROLL, Judith. Bilingual lexical activation in sentence context. Journal of Memory and Language, v. 55, n. 2, p. 197-212, 2006. http://dx.doi.org/ 10.1016/j.jml.2006.03.004 
SCHWARTZHAUPT. Bruno M. Testing intelligibility in English: the effects of positive VOT and contextual information in a sentence transcription task. 2015. 86 fls. Dissertação (Mestrado em Letras) - Universidade Federal do Rio Grande do Sul, 2015.

SCHWARTZHAUPT, Bruno M.; ALVES, Ubiratã K.; ARÊAS DA LUZ FONTES, Ana B. The role of L1 knowledge on L2 speech perception: investigating how native speakers and Brazilian learners categorize different VOT patterns in English. Revista de Estudos da Linguagem, v. 23, p. 311-334, 2015. http://dx.doi.org/10.17851/2237-2083.23.2.311-334

SOARES, Carlos; GROSJEAN, François. Bilinguals in a monolingual and a bilingual speech mode: The effect on lexical access. Memory \& Cognition, v. 12, n. 4, p. 380-386, 1984. http://dx.doi.org/10.3758/BF03198298

SOTO, Marije; FRANÇA, Aniela. I. Aplicação de uma teoria micromodular às hipóteses acerca do acesso lexical bilíngüe: um estudo sobre holandês-português. Revista Virtual de Estudos da Linguagem, v. 6, p. 10, 2008.

VAID, Jyotsna. Bilingualism. Encyclopedia of the Human Brain. Elsevier Science, 2002. Vol. 1, p. 417-434.

Van ASSCHE, Eva; DRIEGHE, Denis; DUYCK, Wouter; WELVAERT, Marijke; HARTSUIKER, Robert J. The influence of semantic constraints on bilingual word recognition during sentence reading. Journal of Memory and Language, v. 64, p. 88-107, 2011. http://dx.doi. org/10.1016/j.jml.2010.08.006

VAN ASSCHE, Eva; DUYCK, Wouter; HARTSUIKER, Robert J. Bilingual Word Recognition in a Sentence Context. Frontiers of Psychology, v. 3, 2012.

Van ASSCHE, Eva; DUYCK, Wouter; BRYSBAERT, Mark. Verb processing by bilinguals in sentence contexts. Studies of Second Language Acquisition, v. 35, n. 2, p. 237-259, 2013. http://dx.doi.org/10.1017/S0272263112000873

Van HELL, Janet. G.; DIJKSTRA, Ton. Foreign language knowledge can influence native language performance in exclusively native contexts. Psychonomic Bulletin \& Review. v. 9, p. 780-789, 2002. http://dx.doi.org/10.3758/BF03196335

Van ORDEN, Guy C. Arows is a rose: spelling, sound, and reading. Memory and Cognition, v. 15, p. 181-198, 1987. http://dx.doi.org/10.3758/BF03197716

ZIMMER, Márcia C. SILVEIRA, Rosane; ALVES, Ubiratã K. Pronunciation Instruction for Brazilians: bringing theory and practice together. Cambridge Scholars Publishing, 2009.

Recebido em 09/11/2015.

Aceito em 26/12/2015. 